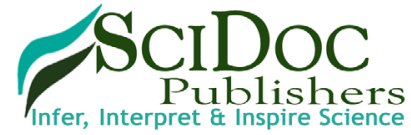

International Journal of HIV/AIDS and Research (IJHR)

ISSN 2379-1586

\title{
Renal Disease in HIV: Practical Aspects for Nephrologists
}

Review Article

Haragsim L*, Grant Z Meltzer

Professor of Medicine, Department of Medicine, University of Oklahoma Health Sciences Center, Oklahoma City, USA.

Patients with HIV represents a unique and often seemingly daunting challenge for nephrologists, as these patients often have many multi-system issues, and are on a mix of medications that are not well known or often prescribed by non-infectious disease specialists. HIV is a risk factor for acute kidney injury (AKI)/ chronic kidney disease (CKD), and there is a wide spectrum of renal disease that occurs in these patients, including those directly caused by the virus, and medication toxicities. Once the renal disease is advanced, these patients can also provoke difficult decisions regarding the issues of kidney biopsy, dialysis, and transplant. The nephrologist requires a working knowledge of the current state of overall HIV management, so that they can help with the prevention and treatment of acute and chronic kidney disease, within the multi-disciplinary HIV team.

Acute kidney injury and chronic kidney disease are common in HIV patients. One study showed a rate of AKI about twice as high in hospitalized HIV patients ( $6 \%$ vs $2.7 \%$ in the controls), and these patients had a mortality of $27 \%$, versus $4 \%$ for the nonHIV controls [1]. A study of ambulatory HIV patients showed a rate of AKI of $9.4 \%$ over a two year period [2]. The rate of chronic kidney disease amongst HIV patients has been found to range from $10-15.5 \%[3,4]$. Because of the high risk of renal disease, the IDSA guidelines recommend screening for kidney disease (with serum creatinine and some measure of proteinuria), whenever there is a change in antiretroviral therapy, and twice yearly if the patient is otherwise stable [5].

Potential mechanisms for HIV as a risk factor for AKI/CKD include direct toxicity of the virus, nephrotoxic medications (including some antiretrovirals and antimicrobials), and frequent/ severe infections that occur as a result of the immunocompromised state. It is important to note that subclinical kidney disease is likely to be present even if there are not yet changes in clinical markers of kidney function. An autopsy study of HIV patients showed histologic changes in the kidney prior to overt clinical
CKD [6]. These factors combine to predispose HIV patients to renal disease from all of the common non-HIV-related causes, such as hypertension and diabetes. Also of note is that hepatitis $\mathrm{C}$ coinfection is associated with higher rates of both AKI and CKD [7] .

There is a wide spectrum of renal disease in HIV, but most causes fit into three categories: HIV infection related, HIV treatment related, or non-HIV related. HIV infection related is defined as disease that is a direct result of the viral infection, including HIVassociated nephropathy (HIVAN), HIV immune complex disease (HIVICK), and HIV thrombotic microangiopathy (HIV-TMA). HIV treatment related causes include the nephrotoxic side effects of antiretrovirals and antimicrobials. Non-HIV related causes must always be considered once HIV infection related and treatment related causes are ruled out, with the understanding that all renal disease in an HIV patient is not necessarily related to the virus and/or its treatment.

HIVAN is the result of viral infection and replication within the kidney. Collapsing focal segmental glomerulosclerosis (FSGS) and tubulointerstitial disease are seen on biopsy [8]. Classically, it presents with heavy proteinuria, a rapid decline in GFR, and a rapid progression to ESRD. There are 800 to 900 ESRD due to HIVAN new cases of per year in the US [9]. One recent study showed biopsy-proven HIVAN to have a $70 \%$ progression to ESRD [10]. HIVAN is seen primarily in African American patients with advanced HIV. 90\% of the ESRD due to HIVAN in the US is in African Americans [9]. The genetic predisposition may be due to a single nucleotide polymorphism in Apolipoprotein L1, that is seen in West African descendants [11]. The primary treatment for HIVAN is antiretroviral therapy, and the IDSA recognizes it as an indication for starting antiretroviral therapy [5]. The incidence of HIVAN has decreased since the widespread use of antiretroviral therapy. One biopsy series showed a HIVAN prevalence of $80 \%$ on kidney biopsies in 1997 ,

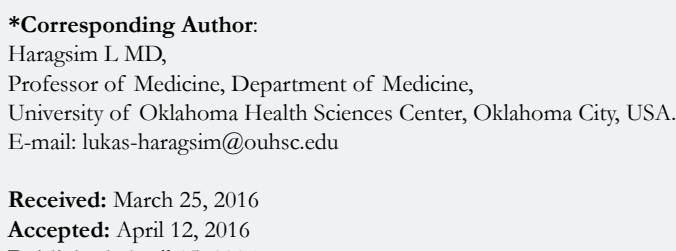

Copyright: Haragsim $\mathbf{L}^{\circ}$ 2016. This is an open-access article distributed under the terms of the Creative Commons Attribution License, which permits unrestricted use, distribution and reproduction in any medium, provided the original author and source are credited. 
which declined to a prevalence of $20 \%$ on kidney biopsies in 2004 [12]. More of the non-HIVAN biopsies showed non-collapsing FSGS, which some believe to represent partially treated HIVAN. These patients present with milder proteinuria and a less severe decrease in GFR [13]. Another hypothesis is that these patients may be predisposed to classic FSGS because of similar genetic predisposition in African Americans. Once HIVAN is diagnosed in a patient not already on antiretroviral therapy, it has been shown to respond to the initiation of antiretroviral therapy [10]. Other specific treatments have been studied for HIVAN, including ACE inhibitors and steroids, however a 2013 Cochrane Review did not find sufficient evidence to make recommendations for either [14]. IDSA guidelines recommend starting ACE inhibitors if HIVAN is suspected, or if there is significant albuminuria [5]. The KDIGO glomerulonephritis guidelines do not make any recommendation for or against ACE inhibitors in these patients [15]. The IDSA guidelines also recommend considering steroids [5], while the KDIGO guidelines make no specific recommendation [15]. The few studies on steroids for HIVAN were done in the era before antiretroviral therapy and included small numbers of patients, though they did show some benefit.They used around $60 \mathrm{mg}$ per day of prednisone and showed no increased incidence of opportunistic infections [16], though one did show an increase in avascular necrosis [17]. Despite this, the difficulty of extrapolating this data to the antiretroviral era has led to steroids not being standard of care in these patients.

HIV immune complex disease is defined as any immune complex disease found on biopsy in the setting of HIV. The etiology of HIVICK is unclear, though some believe it to be caused by antiHIV antibodies promoting immune complex formation. A recent biopsy series showed the most common finding of HIVICK as being post-infectious glomerulonephritis. The next most common was "lupus-like" glomerulonephritis, which was defined as the "full house" of immune complex deposition, with negative lupus serologies. The other cases showed IgA nephropathy, membranoproliferative glomerulonephritis, membranous nephritis, or glomerulonephritis not otherwise specified [10]. Compared to HIVAN, patients with HIVICK present with less proteinuria, more variable renal dysfunction, less fulminant decrease in GFR and less progression to ESRD. Additionally, patients tend to be less immunocompromised at diagnosis. The rate of progression to ESRD was $32 \%$ in one study of biopsyproven cases, and the initiation of antiretroviral therapy after diagnosis of HIVICK was not shown to improve outcomes [10]. No specific treatment that has been shown effective for HIVICK, though the standard specific treatments for the immune complex diseases (i.e. if they were diagnosed outside of the setting of HIV), should be considered.

HIV thrombotic microangiopathy is thrombotic microangiopathy (TMA) thought to be triggered by viral injury to the endothelium. It is seen in advanced HIV and has become less common since the widespread use of antiretroviral therapy [18]. The presentation is similar to TMA in other settings. There is no specific treatment, other than initiation of antiretroviral therapy, and the consideration of standard treatments for thrombotic microangiopathy.

Non-nucleoside reverse transcriptase inhibitors (i.e. efavirenz, etravirine) are generally not nephrotoxic. Nucleoside reverse transcriptase inhibitors (i.e. zidovudine, lamivudine, abacavir, emtricitabine, stavudine, didanosine) are uncommonly nephrotoxic, however they can cause Type B lactic acidosis (highest risk for stavudine and didanosine [19]).

Nucleotide reverse transcriptase inhibitors (i.e. tenofovir) are commonly nephrotoxic. Adefovir and cidofovir are also nucleotide reverse transcriptase inhibitors, however they are not approved for HIV, but are used for hepatitis B and CMV, respectively, and have the same side effect profile. Nucleotide reverse transcriptase inhibitors cause proximal tubular injury/ Fanconi Syndrome and/or nephrogenic diabetes insipidus. Tubular injury can be monitored by watching for glycosuria without elevated blood glucose, FE-Phos $>20 \%$, and/or FE-uric acid $>20 \%$ [5]. Tenofovir deserves special mention, because it is probably the most commonly used nephrotoxic HIV medication. The incidence of AKI due specifically to tenofovir is difficult to determine, however, a recent meta-analysis showed an average decrease in GFR of $3.92 \mathrm{~mL} / \mathrm{min}$, over prolonged periods of followup [20]. There can be increased risk of tenofovir toxicity when it is combined with atazanavir, amprenavir, or ritonavirboosted protease inhibitors [21, 22, 23]. IDSA guidelines recommend avoiding tenofovir in patients with a GFR $<60$ $\mathrm{ml} / \mathrm{min}$, and recommend discontinuing tenofovir if the GFR decreases by $25 \%$ once started [5]. Dolutegravir + abacavir/ lamivudine is a first-line regimen that can be used if tenofovir is being avoided [24].

Protease inhibitors (i.e. indinavir, atazanavir) are commonly nephrotoxic, with mechanisms including crystalluria, kidney stones, tubular obstruction, and/or chronic tubulointerstitial nephritis. These occurred frequently enough with indinavir that it is no longer commonly used. Atazanivir is commonly used, however, and is also associated with significant risk of CKD [25]. Of note, atazanivir can interfere with the metabolism of beta blockers and non-dihydropyridine calcium channel blockers, which could cause hypotension and result in AKI from hemodynamics.

Rilpivirine (non-nucleoside reverse transcriptase inhibitor), cobicistat (boosting agent), and dolutegravir (integrase inhibitor) are all capable of causing a trimethoprim-like increase in creatinine, which is due to decreased tubular secretion of creatinine, and is not an indicator of a true decrease in GFR [26, 27, 28].

HIV does not change the indications for kidney biopsy. A 2005 biopsy series showed that nephrotic-range proteinuria and low CD4 count could not be used to predict HIVAN. Only 53\% of the patients had HIVAN on the biopsy, and $33 \%$ of the patients with CD4 count less than 200 did not have HIVAN [29]. HIV patients have also been shown to not have an increased risk of complications from kidney biopsy [30].

While the rates of ESRD from HIVAN are lower since the introduction of antiretroviral therapy, the increase in life-span attributed to antiretroviral therapy has led to more ESRD from non-HIV-related causes. $1.5 \%$ of dialysis patients in the United States have HIV [31], and 91\% of them are African Americans [9]. In general, HIV patients on dialysis are managed no differently than other dialysis patients, and they are candidates for both hemodialysis and peritoneal dialysis.

Though a relatively new, kidney transplant is a viable option for HIV patients. IDSA guidelines recommend that HIV patients with ESRD be evaluated for kidney transplant [5]. Most of 
the data for kidney transplants in HIV patients in the United States comes from a 2010 cohort, which showed similar overall outcomes in HIV kidney transplants, as compared with the non-HIV transplant controls. The eligibility requirements for this study were a CD4 count greater than 200, an undetectable viral load, and a stable antiretroviral regimen. Exclusion criteria included a history of progressive multifocal leukoencephalopathy, chronic intestinal cryptosporidiosis, primary CNS lymphoma, or visceral Kaposi's sarcoma. Overall 1 and 3 year survival for the HIV transplant patients was $94.6 \%$ and $88.2 \%$, respectively. Graft survival at 1 year was $90.4 \%$, and at 3 years was $73.7 \%$. While the overall outcomes were not significantly different, as compared to the non-HIV controls, the HIV transplant patients did experience significantly higher rates of acute rejection, $31 \%$ versus $12 \%$ in the first year [32]. One potential mechanism for the increased rate of rejection could be because of drug interactions, as protease inhibitors increase calcineurin inhibitor levels, and nonnucleoside reverse transcriptase inhibitors decrease calcineurin inhibitor levels. Some practitioners may also be more hesitant to give higher doses of immunosuppression to HIV patients, due to fears of opportunistic infections. IDSA guidelines recommend considering switching to a raltegravir-based regimen prior to transplant, to minimize interactions with calcineurin inhibitors and sirolimus [5]. However, one study that looked at switching regimens showed that patients on a stable antiretroviral regimen had an increased risk of viral relapse when switching to the raltegravir-based regimen, though it should be noted that this study was not in patients trying to get listed for transplant [33]. So while there may be fewer interactions once switched to the raltegravir-based regimen, there is increased risk of viral relapse, which would delay transplant.

\section{References}

[1]. Wyatt CM, Arons RR, Klotman PE, Klotman ME (2006) Acute renal failure in hospitalized patients with HIV: risk factors and impact on in-hospital mortality. AIDS 20(4): 561-565.

[2]. Franceschini N, Napravnik S, Eron JJ Jr, Szczech LA, Finn WF (2005) Incidence and etiology of acute renal failure among ambulatory HIV-infected patients. Kidney Int 67(4): 1526-1531.

[3]. Fernando SK, Finkelstein FO, Moore BA, Weissman S (2008) Prevalence of chronic kidney disease in an urban HIV infected population. Am J Med Sci 335(2): 89-94

[4]. Wyatt CM, Winston JA, Malvestutto CD, Fishbein DA, Barash I, et al. (2007) Chronic kidney disease in HIV infection: an urban epidemic. AIDS 21(15): 2101-2103.

[5]. Lucas GM, Ross MJ, Stock PG, Shlipak MG, Wyatt CM, et al. (2014) Clinical practice guideline for the management of chronic kidney disease in patients infected with HIV: 2014 update by the HIV Medicine Association of the Infectious Diseases Society of America. Clin Infect Dis 59(9): e96-138.

[6]. Wyatt CM, Morgello S, Katz-Malamed R, Wei C, Klotman ME, et al. (2009) The spectrum of kidney disease in patients with AIDS in the era of antiretroviral therapy. Kidney Int 75(4): 428-434.

[7]. Wyatt CM, Malvestutto C, Coca SG, Klotman PE, Parikh CR (2008) The impact of hepatitis $\mathrm{C}$ virus coinfection on HIV-related kidney disease: a systematic review and meta-analysis. AIDS 22(14): 1799-1807.

[8]. D'Agati V, Suh JI, Carbone L, Cheng JT, Appel G (1989) Pathology of HIVassociated nephropathy: a detailed morphologic and comparative study. Kidney Int 35(6): 1358-1370.

[9]. U.S. Renal Data System (2007) USRDS 2007 Annual Data Report: Atlas of Chronic Kidney Disease and End-Stage Renal Disease in the United States.

[10]. Foy MC, Estrella MM, Lucas GM, Tahir F, Fine DM, et al. (2013) Comparison of risk factors and outcomes in HIV immune complex kidney disease and HIV-associated nephropathy. Clin J Am Soc Nephrol 8(9): 1524-1532.

[11]. Genovese G, Friedman DJ, Ross MD, Lecordier L, Uzureau P, et al. (2010) Association of trypanolytic ApoL1 variants with kidney disease in African Americans. Science 329(5993): 841-845.

[12]. Berliner AR, Fine DM, Lucas GM, Rahman MH, Racusen LC, et al. (2008)
Observations on a cohort of HIV-infected patients undergoing native renal biopsy. Am J Nephrol 28(3): 478-486.

[13]. Ross MJ (2014) Advances in the pathogenesis of HIV-associated kidney diseases. Kidney Int 86(2): 266-274.

[14]. Yahaya I, Uthman OA, Uthman MM (2013) Interventions for HIV-associated nephropathy. Cochrane Database Syst Rev 1: CD007183.

[15]. Kidney Disease: Improving Global Outcomes (KDIGO) Glomerulonephritis Work Group (2012) KDIGO Clinical Practice Guideline for Glomerulonephritis. Kidney Int 2(2): 139-274.

[16]. Eustace JA, Nueremberger E, Choi M, Scheel PJ Jr, Moore R, et al. (2000) Cohort study of the treatment of severe HIV-associated nephropathy with corticosteroids. Kidney Int 58(3): 1253-1260.

[17]. Glesby MJ, Hoover DR, Vaamonde CM (2001) Osteonecrosis in patients infected with human immunodeficiency virus: a case-control study. J Infect Dis 184(4): 519-523.

[18]. Gervasoni C, Ridolfo AL, Vaccarezza M, Parravicini C, Vago L, et al. (2002) Thrombotic microangiopathy in patients with acquired immunodeficiency syndrome before and during the era of introduction of highly active antiretroviral therapy. Clin Infect Dis 35(12): 1534-1540.

[19]. Lactic Acidosis International Study Group (2007) Risk factors for lactic acidosis and severe hyperlactemia in HIV-1 infected adults exposed to antiretroviral therapy. AIDS 21: 2455-2464.

[20]. Cooper RD, Wiebe N, Smith N, Keiser P, Naicker S, et al. (2010) Systematic review and meta-analysis: renal safety of tenofovir disoproxil fumarate in HIV-infected patients. Clin Infect Dis 51(5): 496-505.

[21]. Zimmerman AE, Pizzoferrato T, Bedford J, Morris A, Hoffman R, et al. (2006) Tenofovir-associated acute and chronic kidney disease: a case of multiple drug interactions. Clin Infect Dis 42(2): 283-290.

[22]. Crane HM, Kestenbaum B, Harrington RD, Kitahata MM (2007) Amprenavir and didanosine are associated with declining kidney function among patients receiving tenofovir. AIDS 21(11): 1431-1439.

[23]. Goicoechea M, Liu S, Best B, Sun S, Jain S, et al. (2008) Greater tenofovirassociated renal function decline with protease inhibitor-based versus nonnucleoside reverse-transcriptase inhibitor-based therapy. J Infect Dis 197(1): 102-108.

[24]. Department of Health and Human Services. Guidelines for the use of antiretroviral agents in HIV-1 infected adults and adolescents: 2016. Available at:http://aidsinfo.nih.gov/guidelines/html/1/adult-and-adolescent-treatment-guidelines/0

[25]. Mocroft A, Kirk O, Reiss P, De Wit S, Sedlacek D, Beniowski M, Gatell J, Phillips AN, Ledergerber B, Lundgren JD. Estimated glomerular filtration rate, chronic kidney disease and antiretroviral drug use in HIV-positive patients. AIDS 2010; 24: 1667-78.

[26]. Cohen CJ, Andrade-Villanueva J, Clotet B, Fourie J, Johnson MA, et al. (2011) Rilpivirine versus efavirenz with two background nucleoside or nucleotide reverse transcriptase inhibitors in treatment-naive adults infected with HIV-1 (THRIVE): a phase 3, randomised, non-inferiority trial. Lancet 378(9787): 229-237.

[27]. German P, Liu HC, Szwarcberg J, Hepner M, Andrews J, et al. (2012) Effect of cobicistat on glomerular filtration rate in subjects with normal and impaired renal function. J Acquir Immune Defic Syndr 61(1): 32-40.

[28]. Koteff J, Borland J, Chen S, Song I, Peppercorn A, et al. (2013) A phase 1 study to evaluate the effect of dolutegravir on renal function via measurement of iohexol and para-aminohippurate clearance in healthy subjects. $\mathrm{Br} \mathrm{J}$ Clin Pharmacol 75(4): 990-996.

[29]. Atta MG, Choi MJ, Longenecker JC, Haymart M, Wu J, et al. (2005) Nephrotic range proteinuria and CD4 count as noninvasive indicators of HIVassociated nephropathy. Am J Med 118(11): 1288.

[30]. Tabatabai S, Sperati CJ, Atta MG, Janjua K, Roxbury C, et al. (2009) Predictors of complication after percutaneous ultrasound-guided kidney biopsy in HIV-infected individuals: possible role of hepatitis C and HIV co-infection. Clin J Am Soc Nephrol 4(11): 1766-1773.

[31]. Finelli L, Miller JT, Tokars JI, Alter MJ, Arduino MJ (2005) National surveillance of dialysis-associated diseases in the United States, 2002. Semin Dial 18(1): 52-61.

[32]. Stock PG, Barin B, Murphy B, Hanto D, Diego JM, et al. (2010) Outcomes of kidney transplantation in HIV-infected recipients. N Engl J Med 363: 2004-2014.

[33]. Eron JJ, Young B, Cooper DA, Youle M, Dejesus E, et al. (2010) Switch to a raltegravir-based regimen versus continuation of a lopinavir-ritonavirbased regimen in stable HIV-infected patients with suppressed viraemia (SWITCHMRK 1 and 2): two multicentre, double-blind, randomised controlled trials. Lancet 375(9712): 396-407. 